\title{
Leitura: extensão de mundo
}

\section{Reading: extension of the world}

\section{Lecture: extension du monde}

Benevenuta Fátima de LIMA

Walquiria Therezinha dos Santos AMORIN

\section{RESUMO}

A importância da leitura utilizada tanto na escola quando fora desse ambiente é destacada neste artigo, ao considerar-se que ela continua sendo um dos meios mais utilizados pelo homem para inserir-se no próprio mundo. Da leitura instintiva do universo até a leitura do mundo digitalizado, longo caminho foi percorrido. E para chegar aos dias de hoje, nos quais é grande a presença de artifícios implementados à comunicação, o homem exercitou o pensar e o agir, em uma conquista diária, com esforços incessantes na busca de novos conhecimentos. Como parte deste mundo que possibilita novas dimensões de vida, a escola deve buscar meios propícíos para a inserção de seus professores e alunos no mundo digital, através da leitura de textos diversos, de maneira que o conhecimento desta nova ordem possibilite maior interação e, consequentemente, encontre estímulos reais para fazer a leitura atravessar fronteiras escolares e continuar vida a fora

Palavras-chave: leitura; escola; tecnologia; comunicação._.

\section{ABSTRACT}

The importance of reading as much inside as outside of the classroom is emphasized in this paper, considering that it has remained one of the most frequently used ways by which humans "insert" themselves into the world. From reading that is instinctive about the universe to reading of the digital world, the history of reading is long and complex. To now arrive in modern times, in which the presence of artifices that are implemented for communication is widespread, humans have exercised thought and action as part of a daily conquest, in an incessant effort in search of new knowledge. As a part of this world that makes possible new dimensions of life, schools should look for propitious ways of "inserting" teachers and students into the digital world through the reading of diverse texts. This new knowledge that accompanies this new world order should facilitate greater interaction and 
consequently, finds real incentives to make reading cross frontiers and to continue life "outside of the box."

Index terms: reading; school; technology; communication.

\section{RÉSUMÉ}

Cet article met en évidence l'importance de la lecture utilisée dans l'école autant qu'à l'extérieur. La lecture est aussi en évidence dans cet article parce qu'elle est considérée un des moyens le plus utilisée par les hommes pour entrer dans leur environnement. De la lecture instinctive de l'univers jusqu'à lecture du monde digitalisé, il y a un très grand chemin a été franchi. Pour arriver au moment où il $\mathrm{y}$ a la présence des artifices implémentés à la communication, l'homme a fait un exercice de la pensée et de l'action dans une conquête quotidienne, avec des efforts sans cesse dans la recherche de nouvelles connaissances. Comme partie de ce monde qui permet des nouvelles dimensions de la vie, l'école doit chercher des moyens pour l'insertion de ses professeurs et de ses élèves dans le monde digital à travers la lecture de différents textes. La connaissance de cette nouvelle ordre peut permettre une plus grande interaction et, par conséquenee, elle trouve des stimuli réels pour faire traverser la lecture aux frontières scolaires et continuer la vie dehors de l'école.

Mots- clés: lecture; école; technologie; communication.

\section{Introdução}

O homem desde que existe lê o mundo, o espaço, o ambiente onde vive. No princípio, talvez, uma leitura instintiva, depois passa a ler o cosmo para dele se inteirar, para ficar menos susceptível às forças da natureza ou para dela tirar melhor proveito, seja da terra, da água, do fogo ou do ar. Talvez hoje, continue a lê-lo também para isso. E neste insaciável processo de leitura sai do lar e vai à escola. Nesse caminho tortuoso, se não encontrar, hoje, estímulo contínuo para as diversas leituras de mundo, principalmente para a leitura alfabética, talvez não consiga decodificar apenas o mundo gráfico, mas extrapole a sua incapacidade para além das fronteiras do livro, 
ficando marginalizado pela própria incapacidade de analisar o mundo que o rodeia.

Embora o medo do novo persiga o homem desde os mais remotos tempos, ele continua em busca de novas criações, descoberta e leituras, transformando pela técnica a realidade natural em realidade artificial, com objetivo de subsistir e proteger-se. E nessa perseguição ao novo, lê o seu universo, continuamente, das mais diferentes formas.

Neste mundo concreto, depara-se o "homo sapiens" com o mundo das letras e por elas vive cercado. Se não no seu significado total, pelo menos presenciando um mundo onde o decifrar de um código verbal estereotipado, sistematizado, tido como padrão, se faz necessário como desde a identificação de um produto no supermercado, passando pelo itinerário de um coletivo, vivenciando a busca de informação em placas e sinais diversos, podendo chegar ao balcão de uma farmácia e correr o perigo de levar um medicamento "identificado" por alguém que não o codificou.

Nesse árduo caminho em busca de uma linguagem que torne significativo o próprio mundo, compreende o ser humano que é preciso ler o universo e assim aprender, ler para buscar informação, para conservar a memória da história dos seus antepassados e não repetir os seus erros, para compreender os fundamentos de nossa civilização, para encontrar entretenimento, para aceitar, contestar, exigir, transformar a própria realidade, para melhor se comunicar, enfim, para exercer a tão propalada cidadania, como destaca Rojo (2002, p.2):

(...) ser letrado e ler na vida e cidadania, (...) é escapar da literalidade dos textos e interpretá-los, colocando-os em relação com outros textos e discursos, de maneira situada na realidade social; (...) As práticas de leitura na vida são muito variadas e dependentes de contexto, cada um deles exigindo certas capacidades leitoras e não outras.

Surge, então, a linguagem humana com sua característica-chave de possibilitar ao falante descrever-se a si mesmo e às suas situações de vida, 
de forma que o próprio domínio linguístico passe a fazer parte das interações possíveis, como afirma. Marques (1999). Assim, a linguagem do homem reflete o cosmo em que habita e pouco a pouco vai estabelecendo a sua cultura.

\footnotetext{
Não vemos a realidade como é, senão como são nossas linguagens. E nossas linguagens são nossos meios de comunicação. Nossos meios de comunicação são nossas metáforas. Nossas metáforas criam o conteúdo de nossa cultura. (CASTELLS, 1997, v.1, p. 360).
}

A presença da escrita, embora criada muito tempo após o surgimento da oralidade, hoje se insere fortemente em quase todas as práticas sociais, adquirindo um forte prestígio social Até mesmo os analfabetos, em sociedades gráficas, estão sob a influência da escrita o que contemporaneamente, convencionou-se chamar de práticas de letramento, o que não equivale ao domínio da escrita, mesmo que parcial. Assim, "existem letramentos sociais que surgem e se desenvolvem à margem da escola", como afirma Marcuschi (2007), possibilitando ao indivíduo o uso utilitário da leitura e da escrita em contextos informais.

$\mathrm{Na}$ contemporaneidade, o processo de leitura de um código verbal continua consistindo no desenvolvimento da técnica de saber (ciência) decodificar, interpretar, manifestar a própria visão sobre um assunto visto surgido, talvez, desde o desejo de decodificar dos rolos de papiro e pergaminhos manuscritos - tecnologias da época que englobavam conhecimento na manipulação de misturas derivadas de animais e plantas fazendo surgir as penas e tintas e sua respeitável leitura - passando pelas "sagradas escrituras", pelo advento dos tipos móveis da imprensa de Gutemberg, que conseguiu com a prensa mecânica a produção e duplicação do livro.

A página impressa, de certa forma, fez perder o papel fundamental que tinham os copistas e comentadores dos poetas ao lidar com os 
manuscritos. Isso obedecia a um ritual que ia desde a forma de desenrolar o papiro, passava pelas transcrições e observações textuais de seus predecessores e somavam-se às próprias interpretações. A noção de autoria hoje existente sofria grande interferência. E construindo e ultrapassando os mais diversos caminhos, chegamos ao mundo adjetivado de cibernético, automatizado, tecnológico, digitalizado, eletrônico ou virtual. Portanto, a linguagem, o corpo e a técnica, desde as mais antigas interpretações de mundo constituem extensão do ser humano e cada uma, sistematicamente, exige da outra uma intercomplementação.

Analisando esse caminho desenvolvido pelo homem, consideram-se três distintas fases vivenciadas: A "Muscular Motor", quando a máquina substitui a força muscular, a "Sensório Motor" quando ampliam os sentidos e a fase "Cerebral", ora vivenciada, na qual fica clara a revolução tecnológica como marcador profundo do desenvolvimento sócio-políticoeconômico-cultural do homem moderno que só através do processo educativo consolidará essa relação. cf. Santaela, (1997).

Pierre Levy (1995) enfatiza que "longe de serem os exemplares materiais de uma imutável idéia platônica, são redes de interfaces abertas a novas conexões, imprevisíveis, que podem transformar radicalmente seu significado e uso". Daí, a responsabilidade da escola em conscientizar o professor sobre a necessidade de estar entrosado com tal avanço tecnológico, pois, se antes analfabeto era todo aquele que não sabia ler e escrever, hoje é aquele que não sabe manusear as máquinas, em especial o computador.

\section{Tecnologias de informação}

Nesta segunda década do século XXI, observa-se que englobando a combinação em tempo real da cibernética com as redes telecomunicativas que vão resultar na telemática, as redes eletromagnéticas são expandidas. 
Somem-se a isso as dimensões físicas das atividades humanas e temos o ciberespaço que, segundo Marques (1999) apud Levy (1977):

(...) nos reconduz a uma situação anterior à escrita, mas numa outra escala e numa outra órbita, de vez que a interconexão e o dinamismo do tempo real das memórias em rede faz com que o mesmo hipertexto vivo seja compartilhado na sociabilidade cibernética onde não há mais mensagens separadas de uma comunidade ativa, fervilhante de vida, incluindo as próprias pessoas postas em contato num espaço de interconexão aberto, animado de comunicações transversais, caótico, fervoroso, fractal, que não totaliza mais sentido mais reúne pelo contato, pela interação geral.

Assim, a partir do relacionamento com a máquina, o homem alcançando o ciberespaço, seja através da alteridade da máquina, via terminais automatizados que atendem às suas demandas, sem necessitar de intervenções da inteligência humana, seja através da alteridade humana, vivencia uma nova e ampla comunicação. E sobre esta realidade, Marques (1999) apud Marcondes Filho explica:

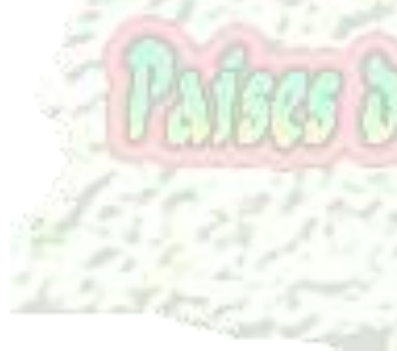

$\mathrm{Na}$ alteridade humana comparece um interlocutor, não em forma física, mas sob forma espectral, imagética, textual ou vocal. Por sua vez o operador não desempenha suas funções de maneira estanque: é ele ao mesmo tempo, espectador, recẻptor, emissor ou agente, que interage com a máquina ao interagir com o outro na extremidade do espaço imaterial.Dessa forma, a interação se faz triádica: envolve o indivíduo interagente, a máquinạ e o outre.

Vivenciamos, pois, a cultura digitalizada, através da edição de imagens via computador, que nos apresenta um "alfabeto icônico", possibilitando-nos o acesso ao hipertexto que, segundo Levy (1995), consiste na idéia de escrita-leitura não linear, formada por um conjunto de nós ligados por conexões, permitindo a construção de bases de dados com acesso associativo, imediato, intuitivo, combinando som, imagem e texto numa estreita articulação de linguagens, favorecendo a criação de um novo ser possuidor de novas habilidades e competências comunicativas. Assim, conforme Marques (1999) apud Virilio, no espaço cibernético a informação 
designa o estado de um fenômeno em determinado momento e encontra-se totalmente contida em sua velocidade de propagação. Assim, a velocidade é a própria informação. Compõe, pois, a última dimensão da matéria-espaçotempo, ou melhor, espaço velocidade, um espaço imaterial constituído na camada eletromagnética do planeta.

Numa retrospectiva temporal verifica-se que, desde a década de 80, novas tecnologias imprimem dinamismo aos meios de comunicação. Se antes era a velha máquina datilográfica, começa a entrar no mercado brasileiro as elétricas com suas esferas impressoras; os jornais começam a vivenciar as publicações periódicas impressas à distância, direcionadas a uma especificidade de público; multiplicam-se os aparelhos portáteis de audição seletiva; videocassete e CD surgem nos mais diferentes ambientes; câmaras de filmagens, do banco à praça, interagem deixando o homem com menos privacidade; filmes de longa metragem podem ser captados pelo computador, por meio do DVD (disco versátil digital), aparelhos musicais MP3, MP4 ou MP5 convivem equilibradamente e, assim, a proliferação das mensagens e fontes faz mais seletiva a audiência, individualiza e aproxima as relações, conseguindo assim a descentralização, a diversificação e a personalização, como afirma Marques (1999):

Ao passar a habitar os suportes dessas novas máquinas, as linguagens assumem formas radicalmente mutantes, são só de fazer as coisas, sobretudo de constituir-se em sociedade e do singularizar-se como sujeito autônomo e competente das corresponsabilidades alargadas em uma concidadania global.

É preciso, contudo, não esquecer que o advento de uma nova tecnologia não anula as anteriores e, na maioria das vezes, comunga de conhecimentos já vivenciados para incorporar novas criações. Assim, o livro impresso não anulou a página manuscrita, o papel e a caneta continuam com sua função; esta última, por sua vez, não foi anulada pela máquina de escrever, o rádio não acabou com o jornal, nem a TV com o cinema, nem a 
informação eletrônica com o livro. Se o computador favorece a colocação da máquina datilográfica em museus, não esquece, no mínimo, a herança do dedilhar do seu teclado, pois como salienta Moran (2010), ensinar e aprender exige hoje muito mais flexibilidade espaço-temporal, pessoal e de grupo, menos conteúdos fixos e processos mais abertos de pesquisa e de comunicação.

Sabe-se que o desenvolvimento humano não pode ser considerado linear, seguindo uma linha reta do princípio ao fim de uma vida, por se ter a certeza de que continuamos a exercer a função que nos distingue dos animais: pensar, interpretar e interferir no próprio mundo, possibilitando novos caminhos para a nossas própria sobrevivência, interagindo nas decisões, mudando a sinuosidade dessa existência.

Assim, diante do surgimento de novas tecnologias, ao buscar a inclusão neste mundo tecnológico, precisamos ter consciência de que passamos a pensar e a ler a dinâmica contemporânea senão influenciados por esses novos processos, pelo menos modificando os nossos hábitos enraizados e deixando envolver-nos por eles, alterando os nossos pensamentos e a nossa visão de mundo, mesmo que isso aconteça num lento processo individual. Esse novo ambiente digital tem gerado discussões quando se analisam os grandes benefícios (ou malefícios?) que as modernas tecnologias impõem ao homem, construindo-lhe um novo ambiente e mudando o próprio modo de ver e pensar a vida, como ressalta Soares (1998, p. 45-46):

\footnotetext{
"à medida que o analfabetismo vai sendo superado, que um número cada vez maior de pessoas aprende a ler e a escrever, e à medida que, concomitantemente, a sociedade vai se tornando cada vez mais centrada na escrita (cada vez mais grafocêntrica), um novo fenômeno se evidencia: não basta aprender a ler e a escrever. As pessoas se alfabetizam, aprendem a ler e a escrever, mas não necessariamente incorporam a prática de leitura e da escrita, não necessariamente adquirem competência para usar a leitura e a
} 
escrita, para

escrita...".

envolver-se com as práticas sociais de

Certamente, as novas tecnologias de informação e comunicação, de leitura e escrita favorecem mudanças significativas na comunicação contemporânea e, lamentamos que, embora seja constatado maior número de crianças na escola, o domínio do processo de leitura não condiz com um Brasil tão pouco inserido no mundo digital.

Assim, observamos que escola necessita consolidar diariamente essas novas práticas. Entretanto, o que testemunhamos muitas vezes é um alinhavar de capacitações docentes que não possibilitam uma segura inclusão nesse mundo digital, mantendo o professor excluído dessa tecnologia e tendo que continuar a se defrontar com o aluno que demonstra uma satisfatória habilidade tecnológica. O processo de ampliação da leitura do professor precisa ser percebido não só como um momento de diminuição dessa "estranheza" diante da máquina, mas que o ajude a mudar a mentalidade profissional. E isso não acontece em "cursos relâmpagos" como os que temos tido oportunidade de presenciar. Assim, Bonilla (2001, p. 40) ratifica esta ideia:

Para isso, o professor deve ser sujeito de sua ação e não mero executor de atividades técnicas, deve ser produtor de conhecimentos e não meramente consumidor, logo, palestras, receitas e cursos rápidos não são suficientes para fazer com que se aproprie de conhecimentos que permitam reconstruir continuamente a sua prática docente.

Se o professor ainda não se encontra devidamente alfabetizado do ponto de vista eletrônico- considerando-se essa alfabetização como sinônimo de construção social- ou seja, ainda tem fragilizada a utilização inteligente e crítica dos instrumentos tecnológicos, não se pode esperar, em curto prazo, a formação de cidadãos que possam exercer a cidadania na sua totalidade. 


\section{Pensamento/conhecimento}

Pensando nesse complexo processo de comunicação e informação que ora vivenciamos e que dá curso à História da humanidade, a fazer da realidade como possivelmente ela é e nos deparamos, mais uma vez, com a dialética do pensar com palavras ou criar palavras para pensar. Não entrando em tão profunda discussão, fixamo-nos no que consiste o pensamento. Paulo Ronca (2001), afirma que o conhecimento não deve ser entendido como um presente divino ou dádiva da natureza. Diz ser uma "conquista quotidiana e laboriosa, um esforço individual que precisa da relação com nossos semelhantes".

Não ensinamos nossos filhos e alunos a pensar, é certo. Contudo, possibilitamos fortalecimento ou aniquilamos essa estrutura mental, através de condições socioculturais que lhes ofereçamos. O pensamento, portanto, é dependente de determinadas situações, dimensões e leituras para que possa continuar a se desenvolver e terá seu fortalecimento à medida que o conhecimento do mundo, das coisas, das idéias surge diminuindo as limitações naturais ou sócio-culturais, evitando lacunas ou desvios. O conhecimento torna-se vital para que o pensamento ganhe força e densidade e que as múltiplas leituras apareçam como conclui, Ronca (2001):

Pensar, então, além de constituir-se numa função de importância impar na vida das pessoas, pode ser considerado um tipo de CPF ou DNA identificador: tal qual um distintivo, conhece-se a pessoa pelo tipo de seu pensamento, tal qual a impressão digital, assume caráter diferenciador tornando-se uma dessemelhança entre os humanos.

Assim, sem o pensamento o conhecimento não se completa. É um ciclo que necessita da percepção sensorial, das sensações, da memorização. E aqui entra a leitura de mundo falada por Paulo Freire. Seja a leitura da percepção da luz do dia, do amarrar do cadarço do tênis, do decodificar de um semáforo, das entrelinhas de um texto, das nossas relações sociais, 
afetivas, funcionais, históricas, enfim, das leituras da nossa vida, o pensamento e o conhecimento se fundem respaldando-se mutuamente, ora ligados ao presente, ora às reminiscências de um passado longínquo ou mais próximo ou na elaboração mental de projetos futuros. E, com uma história, Eduardo Galeano (1995), completa o entendimento:

Diego não conhecia o mar. O pai, Santiago Kovadloff, levou-o para que descobrisse o mar. Viajaram para o sul.

Ele, o mar, estava do outro lado das dunas altas, esperando.

Quando o menino e o pai, enfim alcançaram aquelas alturas de areia, depois de muito caminhar, o mar estava na frente de seus olhos. E foi tanta a imensidão do mar,e tanto o seu fulgor, que o menino ficou mudo de beleza.

E quando, finalmente conseguiu falar, tremendo, gaguejando, pediu ao pai; - Me ajuda a olhar!

Compreender é, portanto, como afirma Paulo Ronca (2001), se fazer autor. É o caminho da autonomia, precisando muitas vezes de ajuda, que circula desde a mãe que diz um não na hora certa, ao pai que "ajuda a olhar", do empreendedor que vislumbra caminhos desconhecidos, até às mensagens televisivas que oferecem caminhos (forçosamente "propícios”) para discussões deste nosso mundo. É fazer com que qualquer fenômeno, fato, texto, contexto ou pessoa adquira uma leitura própria, particular, mesmo que para isso seja preciso a ajuda do outro, favorecendo a geração de novas idéias, a visão de um novo ponto de vista.

Se por um lado o grande poeta Mário Quintana nos lembra de que "aprende-se a escrever lendo, da mesma forma que se aprende a dançar bailando", vejamos o desafio contido no poema "Tecendo a manhã" de João Cabral de Melo Neto (1975): 
Um galo sozinho não tece uma manhã, ele precisará sempre de outros galos. De um que apanhe esse grito que ele e o lance a outro; de outro galo que apanhe o grito de um galo antes e o lance a outro; e de outros galos que com muitos outros galos se cruzem os fios de sol de seus gritos de galo, para que a manhã, desde uma tela tênue, se vá tecendo, entre todos os galos.

Como leitores somos as aves que buscam decodificar o grito do outro durante a nossa existência, recriando sons, evocando idéias, construindo conhecimentos e transmitindo ao semelhante, mesmo longe ou até virtualmente, o que percebemos da nossa realidade. Se a manhã começa no poema com o entrelaçamento do canto dos galos, da sua conexão com outros cantadores, a leitura também necessita da construção de uma rede que possibilite às nossas idéias irem do visual ao digital, entrelaçando-se até formar um novo tecido, uma construção coletiva que amplia a captação do mundo.

Se a arte de tecer começa na roca e desemboca na indústria têxtil ou na reciclagem de matérias que fazem o novo produto, o ato de ler começa na percepção sensorial, viaja pelo pensamento consistente com base no intelectivo, passeia pelas possibilidades das nossas visões de mundo e chega à decodificação num conhecido contexto. Não podemos fixar a leitura do texto como ato individual como foi na sua origem: momento de intimidade e reflexão, contrapondo-se ao caráter coletivo dos contadores de histórias, poetas e eloqüientes oradores, por conhecermos os inúmeros mediadores profissionais da leitura, como professores, bibliotecários, intérpretes, animadores culturais que dispomos, formando, assim, uma cadeia entre o leitor e o significado. Dessa forma, cantadores e tecelões que somos precisamos do outro para nos ouvir e ajudar a tecer conosco as leituras do nosso quotidiano e do amanhã que se avizinha. 
Vale lembrar que no reforço do processo de tecelagem do texto e sua posterior leitura, conta-se com várias habilidades operatórias, fundamentos do pensamento, dentre as quais ressaltamos: identificar, analisar, classificar, argumentar, confrontar, comentar, selecionar, criticar, concluir, tudo isso sem dissociar letramento de alfabetização, pois como destaca Soares (2004) , letramento e alfabetização devem andar juntos, complementando-se, seja na aquisição da escrita pela criança tanto quanto pelo adulto, o que é ratificado pelas atuais concepções linguísticas, psicológicas e psicolinguísticas da leitura e da escrita das diversas práticas sociais. Logo, a escola possibilita o desenvolver desse processo cognitivo, favorecendo ao aluno que essas conquistas possam ser ratificadas continuamente. Assim, é a elaboração individual do pensamento, que passa a ser "original", mesmo sendo pleno de intertextualidades captadas nas nossas vivências. Ao professor cabe intermediar o processo de elaboração de atividades que desenvolvam as competências e habilidades necessárias ao leitor em contínuo processo de decodificação. E é Marisa Lajolo (2004, p.104) quem chama à atenção para esse intermediar do texto quando afirma:

O que se reservam aos professores de hoje, a partir inclusive de sua formação profissional, é a divulgação de-livrôs, a decifração de significados, a intermediação e o patrocínio do consumo de textos impressos. (...) E sé muito incidentalmente, e como por acréscimo, a iniciação de jovens na leitura, talvez porque, em nossa tradição cultural, a leitura como prática coletiva, só exista muito esgarçada mente.

Precisamos, pois, proporcionar aos nossos alunos o exercitar pleno do processo de letramento utilizando competentemente o sistema da língua no contexto das mais variadas práticas sociais que diariamente lhes são apresentadas.

Apostamos, assim, numa escola que propicie aos seus alunos a leitura contínua de textos diversificados que vão do papel ao virtual, do quadro ao computador, da interdisciplinaridade da aula de biologia à de 
literatura, favorecendo um desassossego intelectual e cognitivo através de uma prática curricular como fonte de prazer, de modo que a leitura encontre estímulos para atravessar os portões e continuar vida a fora, fazendo desses leitores - professores e alunos - participantes ativos de um processo contínuo de busca da extensão do próprio mundo.

\section{Considerações finais}

O homem vive num mundo letrado que faz a leitura ocupar um dos papéis decisivos no seu cotidiano. Desde que nasce e começa a ter contato com a realidade, inicia a decodificação do ambiente através dos sentidos, até chegar a outros códigos sistematizados, tornando essa leitura sinônima de conhecimento e de inserção num universo cultural. Aprender a ler significa, pois, pensar o mundo, comunicar-se com ele, dar sentido a si próprio e favorecer a transformação da própria realidade, sistematização esta iniciada no processo de alfabetização escolar e prolongando-se vida a fora via letramento. Aquele que não consegue ler o texto no papel tem poucas chances de melhoria de vida, mas aquele que no mundo contemporâneo não consegue ler o texto digital também está fadado ao insucesso, ou no mínimo, a poucas chances no competitivo mercado de trabalho.

A escola, como espaço dito privilegiado, tem a responsabilidade de garantir aos seus alunos saberes necessários para dar voz ao cidadão e exercitá-lo nessa cidadania, da mesma forma que precisa promover a ampliação progressiva da leitura, de forma que, diante de cada texto que circule socialmente, o cidadão seja capaz de exercer plenamente o processo de letramento que o acompanha desde as séries iniciais. Dessa maneira, poderá interpretar o universo que o circunda, utilizando os mais variados instrumentos de tecnologia e comunicação, interagindo, com o seu meio e participando efetivamente das mais variadas situações sociais. Assim, concretamente, estará propiciando a extensão do próprio mundo. 


\section{Referências bibliográficas}

BONILlA, M. H. S.. Inclusão Digital e Formação de Professores. Revista de Educação, Lisboa, 2001.

CASTELLS, M.. La era de la información: economia, sociedad y cultura. La sociedad red. Madrid: Alianza Editorial, 1977.V.1.

GALEANO, E.. O livro dos abraços. Trad. de Eric Nepomuceno. $4^{\text {a }}$ edição, Porto Alegre: L\&PM, 1995.

LAJOLO, M.. Do mundo da leitura para a leitura do mundo. São Paulo: Ática, 2004.

LEVY, P.. Cibercultura. São Paulo: Editora 34, 1999.

As tecnologias da inteligência: o futuro do pensamento na era da informática. Rio de Janeiro: Editora 34,1995

MARCUSCHI, L. A. Da fala para a escrita: atividades de retextualização. São Paulo: Cortez, 2007.

MARQUES, M.. O. A escola no computador: linguagens rearticuladas, educação outra. Ijuí: Ed. UNIJUÍ, 1999.

MELO NETO, J. C. de. Poesias Completas. $2^{a}$ ed. Rio de Janeiro: José Olympio, 1975.

MORAN,--J. M.. Ensino e Aprendizagem Inovadores com Tecnologias Audiovisuais e Telemáticas. In: MORAN, J. M., MASETTO, M. T, BEHRENS, M.. A. Novas tecnologias e mediação pedagógica. $17 \mathrm{Ed}$. Campinas: Papirus, 2010.

RONCA, P. A. C.. O pensamento parece uma coisa à-toa... Caminhos que ligam o pensar ao conhecimento. São Paulo: Editora do Instituto Esplan, 2001.

ROJO, R. H. R.. A concepção de leitor e produtor de textos nos PCNs: ler é melhor do que estudar. In M. T. A. Freitas \& S. R. C. (orgs). Leitura e Escrita na Formação de Professores. SP: Musa/UFJF/INEP-COMPED, 2002, p. 31-52. 
SANTAELA, L. O homem e as máquinas. A arte do século XXI: Humanização das tecnologias. DOMINGUES D. (org.) São Paulo: Fapesp, 1997.

SOARES, M. Letramento: um tema em três gêneros. Belo Horizonte: Ceale/Autêntica, 1998.

Letramento e alfabetização: as muitas facetas. Revista

Brasileira de Educação. Belo Horizonte. Jan/Fev/Mar/Abr.n.25.2004.

\section{Autoras}

Benevenuta Fátima de LIMA

UNEB

Contato: benevenutafatima@hotmail.com

Walquiria Therezinha dos Santos AMORIN

DCH - Campus IX-UNEB

Contato: walth@uol.com.br

Artigo recebido em março de 2012.

Artigo aprovado para publicação em junho de 2012.

\section{Como citar este texto:}

LIMA, B. F. AMORIN, W. T. S.. Leitura: extensão de mundo. Revista Acolhendo a alfabetização nos países de língua portuguesa, Brasil, São Paulo, volume 1, $\mathrm{n}^{\mathrm{o}}$. 13, pp.65 - 79, Set. 2012. Disponível em: <http://www.acoalfaplp.net>. 